\title{
Synthesis of Nickel and Zinc-Doped Aluminogallate Nanocomposite Spinels with the Hydrothermal Method and Wet Atomization for NO Reduction
}

\author{
Md. Hasan Zahir ${ }^{1,2} \cdot$ Shamseldin A. Mohamed ${ }^{1} \cdot$ Toshio Suzuki $^{3}$
}

Received: 14 September 2015 /Revised: 6 January 2016 / Accepted: 25 January 2016 / Published online: 7 March 2016

(C) Springer International Publishing Switzerland 2016

\begin{abstract}
The levels of nitrogen oxides $\left(\mathrm{NO}_{\mathrm{x}}=\mathrm{NO}+\mathrm{NO}_{2}\right)$ released from both portable and standing combustion devices are on the increase, which contributes to serious environmental problems such as global warming and air pollution. The selective catalytic reduction (SCR) of $\mathrm{NO}_{\mathrm{x}}$ by hydrocarbons (HCs) is very effective, so there have been many studies of the performance of various catalysts for HC-SCR. In this study, $\mathrm{Ga}_{2} \mathrm{O}_{3}-\mathrm{Al}_{2} \mathrm{O}_{3}-\mathrm{NiO}-\mathrm{ZnO}$ (GANZ) nanocomposite metal oxides were tested as catalysts for $\mathrm{NO}_{\mathrm{x}}$ reduction by $\mathrm{C}_{2} \mathrm{H}_{4}$. The spinel metal oxide powders were prepared with the hydrothermal reaction method. Aluminum, gadolinium, nickel, zinc nitrate, and ammonium carbonate salts are highly water soluble and were used in these syntheses. The hydrothermally synthesized powders were then processed with wet atomization to obtain highly dispersed fine particles. Finally, the spinel powders were tested in $\mathrm{NO}_{\mathrm{x}}$ reductions performed in the presence of high levels of oxygen and at a high space velocity, which are demanding conditions since most reported catalysts are not active in this environment. The synthesized product is an uncontaminated spinel phase of GANZ and was found to exhibit high catalytic activity even in the presence of $10 \% \mathrm{H}_{2} \mathrm{O}$ vapor and $\mathrm{SO}_{2}$ at a high space velocity. GANZ
\end{abstract}

Md. Hasan Zahir

hzahir@kfupm.edu.sa

1 Center of Research Excellence in Renewable Energy, Research Institute, King Fahd University of Petroleum and Minerals, Dhahran 31261, Saudi Arabia

2 Center of Research Excellence in Nanotechnology, King Fahd University of Petroleum and Minerals, Dhahran 31261, Saudi Arabia

3 Advanced Manufacturing Research Institute, National Institute of Advanced Industrial Science and Technology, Nagoya, Japan catalysts were also synthesized with the co-precipitation and sol-gel methods for comparison.

Keywords Ceramics $\cdot$ Oxides $\cdot$ Precipitation $\cdot$ Sol-gel growth

\section{Introduction}

$\mathrm{NO}_{\mathrm{x}}$ is a very toxic pollutant that leads to acid rain and photochemical smog. Indeed, prolonged exposure to $\mathrm{NO}_{\mathrm{x}}$ can cause violent coughing, difficulty in breathing, and cyanosis, which can be fatal. The main sources of $\mathrm{NO}_{\mathrm{x}}$ are vehicles and electric devices, as well as industrial, commercial, and residential sources that utilize fuels for energy [1]. The quantities of exhaust produced by vehicles, which are major contributors to $\mathrm{NO}_{\mathrm{x}}$ emissions, are consistently in the upslope due to increasing number of vehicles as well as all kind of road transport. $\mathrm{NO}_{\mathrm{x}}$ undergoes a photochemical reaction stimulated by the ultraviolet rays in sunlight to produce toxic ozone, which is harmful to plants and humans alike. $\mathrm{NO}_{\mathrm{x}}$ also reacts with water in the atmosphere to form a toxic acid, which contaminates water in lakes, rivers, and soil, and causes acid rain [2]. Acid rain is very dangerous to plants and animals. The development of high-performance ceramics as active materials and of innovative manufacturing processes for these materials is considered crucial to attempts to address these problems.

$\mathrm{NO}_{\mathrm{x}}$ can be directly decomposed by a catalytic reaction that requires no reducing agent. This direct decomposition has the products $\mathrm{N}_{2}$ and $\mathrm{O}_{2}$ and could, in principle, be very economical. However, direct decomposition rates are very low for all reported catalysts under real conditions, i.e., in the presence of $2-10 \% \mathrm{O}_{2}, \mathrm{H}_{2} \mathrm{O}$ vapor, and $\mathrm{SO}_{2}$ and at high space velocities. Therefore, it is essential in $\mathrm{NO}_{\mathrm{x}}$ reductions to use a reducing agent such as hydrocarbon (HC)-selective catalytic reduction (SCR) [3]. Single metal oxides, multiple 
metal composite oxides, and zeolites doped with transition metals have been tested for $\mathrm{NO}_{\mathrm{x}}$ reduction in the presence of $\mathrm{H}_{2} \mathrm{O}$ vapor [4]. Zeolite catalysts are not suitable for SCR of $\mathrm{NO}_{\mathrm{x}}$ by $\mathrm{HC}$ because of their instability in the presence of $\mathrm{H}_{2} \mathrm{O}$ vapor [5]. In general, the catalytic activities of these materials diminish significantly with time in the presence of $\mathrm{H}_{2} \mathrm{O}$ vapor, $\mathrm{SO}_{2}$, and particulates. Three-way catalysts (TWCs) for $\mathrm{NO}_{\mathrm{x}}$ reduction were tested in the USA and Japan in 1977. TWCs can retain their high performance when the exhaust feed gas settings are adjacent to the stoichiometric point. However, airfuel proportions are not constant in actual vehicle use. In fact, TWCs are ineffective in the reduction of $\mathrm{NO}_{\mathrm{x}}$ under oxygenrich conditions [5].

It has been reported that $\gamma$ phase $\mathrm{Al}_{2} \mathrm{O}_{3}$ and metal oxidedoped $\gamma-\mathrm{Al}_{2} \mathrm{O}_{3}$ are very effective catalysts for the reduction of NO by hydrocarbons [6, 7]. Many metal oxides, particularly those of the transition metals $\mathrm{Zn}, \mathrm{Fe}, \mathrm{Co}, \mathrm{Cu}, \mathrm{Ag}$, and Pt, have been tested as dopants for enhancing the catalytic activities of $\gamma-\mathrm{Al}_{2} \mathrm{O}_{3}$ [8]. It is well known that metal oxide-doped $\gamma-\mathrm{Al}_{2} \mathrm{O}_{3}$ catalysts are stable with respect to the presence of $\mathrm{H}_{2} \mathrm{O}$ vapor and $\mathrm{SO}_{2}$. Further, a $\gamma-\mathrm{Ga}_{2} \mathrm{O}_{3}-\mathrm{Al}_{2} \mathrm{O}_{3}(\mathrm{GA})$ solid solution has been shown to be an effective catalyst for the reduction of $\mathrm{NO}_{\mathrm{x}}$ by hydrocarbons [9-11]. However, this GA catalyst is unreliable because the solid solution is based on the $\gamma$ phase and must change its phase for increasing temperature in practical application system [12]. The chemical formula of the spinel is $\mathrm{AB}_{2} \mathrm{O}_{4}$, where $\mathrm{A}$ is a divalent $(\mathrm{Ni}, \mathrm{Zn}$, or $\mathrm{Co}$ ) metal cation that resides in a tetrahedral site and $\mathrm{B}$ is a trivalent metal cation (Al) that typically occupies the octahedral sites of the cubic lattice. Oxide-based spinels have been used as magnetic materials, pigments, refractory materials, and catalysts [13-15]. The stability of Ni-doped $\mathrm{Al}_{2} \mathrm{O}_{3}$ as a support is higher than those of other supports [14]. The surface area of a $\mathrm{NiAl}_{2} \mathrm{O}_{4}$ spinel is usually very high, irrespective of the synthesis method. This high surface area has a large impact on catalytic applications. In general, if the particle sizes in a material are very small, then it has a high surface area. Thus, we synthesized nanosized $\mathrm{Ni}$-doped $\mathrm{Al}_{2} \mathrm{O}_{3}-\mathrm{Ga}_{2} \mathrm{O}_{3}$ spinel powders to assess their catalytic properties.

The synthesis of a spinel via a solid-state reaction requires the mechanical mixing of the oxide powders and subsequent sintering at a temperature of approximately $1000{ }^{\circ} \mathrm{C}$. With this method, spinel powders with a low surface area will be obtained due to the high-temperature sintering. In contrast, spinels with surface areas of $100 \mathrm{~m}^{2} \mathrm{~g}^{-1}$ can easily be obtained via the co-precipitation of metal hydroxides or nitrates followed by calcination at temperatures between 750 and $1000{ }^{\circ} \mathrm{C}$. However, the co-precipitation method typically produces a non-homogeneous final product with various particle sizes and compositions [16]. It has been reported that spinels with a surface area of $16 \mathrm{~m}^{2} \mathrm{~g}^{-1}$ can be obtained by using highly water-soluble tartrates or citrate metal salts [17]. These synthesized products need to be calcined at $900{ }^{\circ} \mathrm{C}$. It is well known that low surface areas in the range $10-15 \mathrm{~m}^{2} \mathrm{~g}^{-1}$ are inadequate for catalytic applications. It is important to mention that the catalytic efficiency is typically dependent on catalyst surface area. Spinels with specific surface areas up to $200 \mathrm{~m}^{2} \mathrm{~g}^{-1}$ can easily be obtained with sol-gel processes [18]. In this method, the elements become uniformly distributed during the gel formation step. However, the sol-gel process is very expensive because of the cost of alkoxide-type materials. The authors prepared a $\mathrm{Ga}_{2} \mathrm{O}_{3}-\mathrm{Al}_{2} \mathrm{O}_{3}-\mathrm{NiO}$ (GAN) spinel with a surface area of approximately $220 \mathrm{~m}^{2} \mathrm{~g}^{-1}$ by means of a sol-gel method. Our TEM observations show that the GAN powder consists of peanut-type rod-like grains with a width of approximately $5 \mathrm{~nm}$, which raises the concern that the catalyst's surface area could decrease due to agglomeration and/or the presence of rod-like grains during NO reduction in the presence of $\mathrm{H}_{2} \mathrm{O}$ vapor at high temperatures [19]. In our previous study, GAZ $\left(\mathrm{Ga}_{2} \mathrm{O}_{3}-\mathrm{Al}_{2} \mathrm{O}_{3}-\mathrm{ZnO}\right)$ powders showed a smaller surface area than that of GAN. Despite the lower surface area, GAZ powders exhibited a high catalytic activity similar to GA [10]. It was observed that the simultaneous addition of $\mathrm{NiO}$ and $\mathrm{ZnO}$ to the GA could enhance the catalytic activity $[9,10]$. It was therefore of interest to examine the changes in the NO reduction activity caused by the addition of double dopants $\mathrm{NiO}$ and $\mathrm{ZnO}$ into the GA. The performance of the GA catalysts containing double dopants $\mathrm{NiO}$ and $\mathrm{ZnO}$ was like that of typical zeolite-based catalysts, and NO reduction activity was found to be somewhat higher over the temperature range of $300-500{ }^{\circ} \mathrm{C}$ [11]. However, in the presence of $\mathrm{H}_{2} \mathrm{O}$ vapor, the catalytic activity of $\mathrm{NiO}$ and $\mathrm{ZnO}$ containing GA decreased (ca. $30 \%$ ) with time. Note that the catalysts were prepared by co-precipitation method [10].

Thus, we attempted to prepare a GANZ nanocomposite with fine grains by using a new synthesis route in order to obtain catalytically active materials that can withstand the presence of $\mathrm{H}_{2} \mathrm{O}$ vapor: the spinel catalysts were synthesized with the hydrothermal method, and the synthesized powders were processed with wet atomization. The hydrothermal method is normally performed in aqueous solution at lower temperatures in the range $100-200{ }^{\circ} \mathrm{C}$ in pressurized vessels and has been used to prepare advanced functional materials relatively at low temperature [20]. With this method, fine, high-purity, homogeneous powders can be synthesized from single and/or multicomponent metal oxides. High chemical homogeneity is one major advantage of the hydrothermal method, which makes it attractive for the synthesis of complex oxides such as spinel. The main objective of this study was to prepare GANZ nanocomposites with fine grains. The wet atomization process is a novel method for mixing and distribution and has proved particularly useful in the fields of food technology and chemical engineering [21]. A very short reaction period, particle size reduction, and homogenization can be achieved by using this method. The atomizer system can generate high pressures and eventually produces fine particles 
with homogeneous dispersion. In a high-pressure atomizer, the liquid solution sample is passed through an extremely narrow gap at high speed, which produces very fine powders with large surface areas.

In this study, nanosized GANZ powders were synthesized and tested in $\mathrm{NO}$ reduction by hydrocarbon in the presence of $\mathrm{H}_{2} \mathrm{O}$ vapor and $\mathrm{SO}_{2}$ at a high space velocity to assess their catalyst properties under real $\mathrm{NO}_{\mathrm{x}}$ reduction conditions. We also synthesized GANZ powders with the co-precipitation and sol-gel methods for comparison.

\section{Experimental Details}

\subsection{Development of High-Performance Materials}

Materials: $\mathrm{Ga}_{2} \mathrm{O}_{3}, \mathrm{Al}_{2} \mathrm{O}_{3}, \mathrm{NiO}$, and $\mathrm{ZnO}$ nanocomposite with a high surface area. Synthesis methods: co-precipitation, solgel, hydrothermal, and wet atomization.

\subsection{Synthesis}

In this study, spinel catalysts were prepared by using three different synthesis methods for comparison and to identify the best synthesis route. It has been shown that the selection of preparation technique is very important for catalyst stability and performance [7].

\subsection{Co-Precipitation}

$\mathrm{Ga}(\mathrm{NO})_{3} \cdot 4 \cdot 7 \mathrm{H}_{2} \mathrm{O}, \mathrm{Al}\left(\mathrm{NO}_{3}\right)_{3} \cdot 9 \mathrm{H}_{2} \mathrm{O}, \mathrm{Ni}\left(\mathrm{NO}_{3}\right)_{2} \cdot 6 \mathrm{H}_{2} \mathrm{O}$, and $\mathrm{Zn}\left(\mathrm{NO}_{3}\right)_{2} \cdot 6 \mathrm{H}_{2} \mathrm{O}$ were used as raw materials. All materials were from Kojundo Chemical Co., Japan. GANZ powder sample was prepared with the co-precipitation method by a molar ratio of $\mathrm{Ga} / \mathrm{Al} / \mathrm{Ni} / \mathrm{Zn}=30: 35: 25: 10 \mathrm{~mol} \%$. An aqueous solution was prepared by dissolving transition metal nitrate salts. The precipitation of the metallic ions was induced by the addition of ammonium carbonate salt. The solution $\mathrm{pH}$ was kept at approximately 8.5, and the solution was agitated for $24 \mathrm{~h}$. The obtained products were washed by centrifugation with distilled water and alcohol four times. The powder sample was dried at $110{ }^{\circ} \mathrm{C}$ and calcined at $800{ }^{\circ} \mathrm{C}$ for $2 \mathrm{~h}$ in air.

\subsection{Sol-Gel Method}

GANZ catalyst powder was also synthesized with a sol-gel process. The aluminum boehmite $(\gamma-\mathrm{AlO}(\mathrm{OH}))$ sol was prepared by hydrolyzing aluminum(III) tri-isopropoxide in hot water $\left(90^{\circ} \mathrm{C}\right)$ under inert conditions. To obtain a clear solution, a small amount of nitric acid was added, and then, the metal nitrates were mixed with a molar ratio of $\mathrm{Ga} / \mathrm{Al} / \mathrm{Ni} /$ $\mathrm{Zn}=30: 35: 25: 10 \mathrm{~mol} \%$. The sol solution was stirred for $12 \mathrm{~h}$.
Solvents were removed by heating at $60{ }^{\circ} \mathrm{C}$ for $24 \mathrm{~h}$, and the residues were dried and calcined at $600{ }^{\circ} \mathrm{C}$ for $2 \mathrm{~h}$ in air.

\subsection{Hydrothermal Method}

The hydrothermal method is an interesting strategy for the synthesis of multicomponent oxide-based powders because of the resulting high chemical homogeneity. Fine powders with large surface areas can be directly synthesized with the hydrothermal method, which means that high-temperature calcinations and milling processes are not required. In the synthesis of the GANZ spinel, the nitrate salts of $\mathrm{Ga}, \mathrm{Ni}, \mathrm{Zn}$, and $\mathrm{Al}$ were used as raw materials. The contents of $\mathrm{Ga}_{2} \mathrm{O}_{3}$, $\mathrm{Al}_{2} \mathrm{O}_{3} \mathrm{NiO}$, and $\mathrm{ZnO}$ were $30,35,25$, and $10 \mathrm{~mol} \%$, respectively. The nitrate salts were dissolved in distilled water. $\left(\mathrm{NH}_{4}\right)_{2} \mathrm{CO}_{3}$ was added to the solution to co-precipitate metallic ions and prepared a solution with a $\mathrm{pH}$ approx. 8.5, and then, the solution was vigorously stirred for $24 \mathrm{~h}$. The precursor suspension was transferred into a plastic container with an inner volume of $30-50 \mathrm{~cm}^{3}$ held in a steel vessel. $\mathrm{N}_{2}$ gas was flushed through the suspension for $10 \mathrm{~min}$. The mouth of the vessel was closed, and the hydrothermal reaction was performed at $200{ }^{\circ} \mathrm{C}$ for $48 \mathrm{~h}$. An autoclave with a capacity of $500 \mathrm{~mL}$ and a magnetically driven stirrer (Model TPR-1, Taiatsu Techno) was used for this hydrothermal reaction. The system was then allowed to cool to room temperature. The final product was collected by filtration and washed by centrifugation with alcohol and deionized water three times and decantation with deionized water to remove undesirable anions followed by drying in an oven for $24 \mathrm{~h}$ at $120{ }^{\circ} \mathrm{C}$. These powders are indicated as the "as-synthesized" samples.

\subsection{Wet Atomization}

Wet atomization is a new method for mixing and dispersion that is particularly useful in the fields of food technology and chemical engineering [21]. The "Star Burst System" HJP25001 (Sugino Machine Ltd.) was used for the atomization of the hydrothermally synthesized GANZ slurry and/or solution. The ceramic ball, rubber band, and inside parts of the star burst system were washed in distilled water before operation. The round-shaped steel device with an extremely narrow hole was washed in distilled water, and 30-min ultrasonic cleansing was performed in ethanol. A very short processing period, particle size reduction, and homogenization can be achieved by using this system. This system can generate high pressures in the range 100 200 MPa, which produce fine particles and homogeneous dispersions. In high-pressure atomization, the liquid is passed through an extremely narrow hole at high speed. As a result, we were able to obtain very fine powders with large surface areas. Heat is generated from the kinetic energy of the liquid flowing at high speed during the atomization period, so the higher the pressure, the greater the 
temperature rise in the liquid, which promotes deterioration of the dispersion liquid component and agglomeration of the particles. The fluid flow pressure and number of cycles of atomization were optimized for the highly dispersed GANZ slurry.

After hydrothermal synthesis, the obtained powders were wet-atomized by an addition of ethyl alcohol. By changing the fluid flow, pressure namely 100, 150, and $200 \mathrm{MPa}$, and repeating the atomization process up to five times, an optimum parameter has been fixed for highly dispersed GANZ slurry. The mean particle size's diameter was very small after atomizing three times at a pressure of $150 \mathrm{MPa}$. The particle size distribution was shifted slightly to higher values after repeating the slurries five times. Therefore, the rest of the atomization process was carried out by following the three-time pressure cycle process at a pressure of $150 \mathrm{MPa}$. The slurries were collected into a container after each step of atomization and finally dried at $110{ }^{\circ} \mathrm{C}$. These powders are indicated as the as-synthesized samples.

\subsection{Characterization}

X-Ray Diffraction (XRD) patterns were obtained by using an X-ray diffractometer (Rigaku Denki Co., Tokyo, Japan, RINT-2000 V) with a $\mathrm{CuK} \alpha$ radiation source operating at $50 \mathrm{keV}$ and $200 \mathrm{~mA}$ with a monochromator over a diffraction angle range $2 \theta$ from $10^{\circ}$ to $80^{\circ}$ at a scan rate of $2 \% \mathrm{~min}$. Nitrogen adsorption and desorption experiments were conducted with a Quantachrome Autosorb-IC automated gas sorption system (Quantachrome Instruments Co., Boynton Beach, FL). Before the measurements, the samples were first degassed at $350{ }^{\circ} \mathrm{C}$ for $3 \mathrm{~h}$ under vacuum. The pore size distribution measurements were conducted directly on the powders by using a nano-perm porometer (Seika, Japan). The morphologies and thicknesses of the powders were determined with scanning electron microscopy (SEM; Hitachi S-4500, Tokyo, Japan, operated at $20 \mathrm{keV}$ ). The microstructures of the powders were characterized by performing TEM with a JEM-3000F (300 kV, JEOL Co., Japan). A laser diffraction method was used to measure the particle sizes of the powders, and their surface areas were determined with the nitrogen adsorption technique, i.e., the Brunauer-EmmettTeller method.

\subsection{Catalytic Activity Measurements}

A Pyrex glass tubular reactor with an internal diameter of $12 \mathrm{~mm}$ was used in the catalytic performance tests. The samples were retained between glass wool plugs in the reactor. A mass flow controller was used to control the gas flow rate. A four-channel electronic mass flow controller was used to fix the total flow rate at a constant value. The furnace temperature was increased at a linear heating rate of approx. $10 \mathrm{~K} \mathrm{~min}^{-1}$ with a computer-based temperature controller. Before the performance tests, the total system was activated by increasing the temperature from 200 to $700{ }^{\circ} \mathrm{C}$ under real feed conditions. Data was collected during cooling from 700 to $200{ }^{\circ} \mathrm{C}$ every $60{ }^{\circ} \mathrm{C}$ after 40 -min stabilization at each selected temperature point. During the $\mathrm{H}_{2} \mathrm{O}$ vapor and $\mathrm{SO}_{2}$ poisoning tests, $10 \% \mathrm{H}_{2} \mathrm{O}$ vapor and 3 ppm $\mathrm{SO}_{2}$ were inserted into the gas mixture with a micropump. The catalytic activities were determined in a flowing gas containing 1000-2000 ppm NO, $10 \% \mathrm{O}_{2}, 3-10$ ppm $\mathrm{SO}_{2}$, and $2-10 \% \mathrm{H}_{2} \mathrm{O}$ diluted in $\mathrm{He}$; catalysts weight $0.18 \mathrm{~g}$; and gas hour space velocity (GHSV) $20,000 \mathrm{~h}^{-1}$. Gas chromatography and a molecular sieve were used to analyze the effluent gas at intervals of $20 \mathrm{~min}$. By using an empty catalyst test station, an experiment was performed by flowing the original feed to verify that no $\mathrm{NO}_{\mathrm{x}}$ reduction occurs in the absence of catalyst.

$\mathrm{NO}$ and hydrocarbon conversion were calculated based on the hydrocarbon intake to obtain the NO reduction percentage. The NO conversion and the hydrocarbon conversion to $\mathrm{CO}_{\mathrm{x}}$ $\left(\mathrm{CO}+\mathrm{CO}_{2}\right)$ were calculated based on the following expressions. The percentage error in the calculation data should be less than $2 \%$.

NO conversion to $\mathrm{N}_{2}(\%)=\left\{2\left[\mathrm{~N}_{2}\right] /[\mathrm{NO}]^{\mathrm{in}}\right\} \times 100$

$\mathrm{C}_{2} \mathrm{H}_{4}$ conversion to $\mathrm{CO}_{2}(\%)=\left\{(1 / 2)\left[\mathrm{CO}_{2}\right] /\right.$ $\left.\left[\mathrm{C}_{2} \mathrm{H}_{4}\right]^{\mathrm{in}}\right\} \times 100$

The third bracket denotes the feed concentration, and $[\mathrm{NO}]^{\text {in }}$ and $\left[\mathrm{C}_{2} \mathrm{H}_{4}\right]^{\text {in }}$ are the initial concentrations of $\mathrm{NO}$ and $\mathrm{C}_{2} \mathrm{H}_{4}$, respectively. $\left[\mathrm{N}_{2}\right]$ and $\left[\mathrm{CO}_{2}\right]$ are the final (after testing) concentrations of $\mathrm{N}_{2}$ and $\mathrm{CO}_{2}$.

\subsection{Durability at a High Space Velocity}

The durability of the spinels at high space velocities was tested to confirm whether the catalysts are effective under real $\mathrm{NO}_{\mathrm{x}}$ reduction conditions. Durability was tested for $100 \mathrm{~h}$ in the presence of $10 \% \mathrm{H}_{2} \mathrm{O}$ vapor and $\mathrm{SO}_{2}$.

\section{Results and Discussion}

\subsection{Characterization of Catalysts}

The XRD pattern of a $\mathrm{Ga}_{2} \mathrm{O}_{3}-\mathrm{Al}_{2} \mathrm{O}_{3}-\mathrm{NiO}-\mathrm{ZnO}$ powder prepared with the hydrothermal method is shown in Fig. 1. The composition of the starting materials was $\mathrm{Ga} / \mathrm{Al} / \mathrm{Ni}$ / $\mathrm{Zn}=30: 35: 25: 10 \mathrm{~mol} \%$. Of $\mathrm{Ga}_{2} \mathrm{O}_{3}, 30 \mathrm{~mol} \%$ was used because this percentage was found to result in a $\mathrm{Ga}_{2} \mathrm{O}_{3}-\mathrm{Al}_{2} \mathrm{O}_{3}$ system with the highest catalytic activity [10]. The asprepared powders were amorphous whereas the samples calcined at $800{ }^{\circ} \mathrm{C}$ are crystalline. The XRD pattern contains diffraction peaks and confirms that the synthesized product is a spinel-type material. All the peaks matched well with the characteristic reflections of spinel (JCPDS card 780546). The $\mathrm{Al}_{2} \mathrm{O}_{3}$ polymorph has a lattice parameter $a_{\mathrm{o}}=790.5 \mathrm{pm}$ 


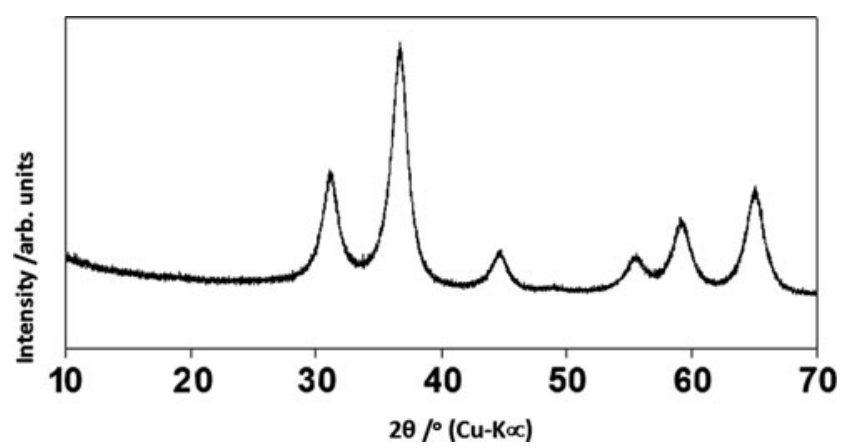

Fig. 1 X-ray diffraction pattern of a GANZ powder sample prepared with the hydrothermal method $(\mathrm{Ga} / \mathrm{Al} / \mathrm{Ni} / \mathrm{Zn}=30: 35: 25: 10 \mathrm{~mol} \%)$

and is known to dissolve (in all proportions) in many spineltype aluminates [18, 22]. No diffraction lines other than those corresponding to a single spinel-type phase were observed and provide strong evidence for spinel [22]. The main focus of this study is the development of homogeneously dispersed fine particles which is crucial for NO reduction under real application conditions. The following sections discuss the SEM and TEM images of GAN powders prepared with the co-precipitation, sol-gel, and hydrothermal methods, followed by wet atomization processing. Finally, the powders were tested as catalysts in NO reductions. Note that our previous study showed that GAN and GANZ powders prepared with the co-precipitation and sol-gel methods do not exhibit good hydrothermal stability $[7,10,11]$.

The GANZ powder prepared with the co-precipitation method consists of nanoparticles, as shown in Fig. 2. This powder was heat-treated at $800{ }^{\circ} \mathrm{C}$ for $2 \mathrm{~h}$ in air and found to have a surface area of approx. $102 \mathrm{~m}^{2} / \mathrm{g}^{-1}$. Figure 3 shows the TEM morphologies of $\gamma-\mathrm{Al}_{2} \mathrm{O}_{3}, \mathrm{GA}$, and GANZ powders synthesized with the sol-gel process. The $\gamma-\mathrm{Al}_{2} \mathrm{O}_{3}$ sample has a scattered cloud-like morphology in which needle-like fine

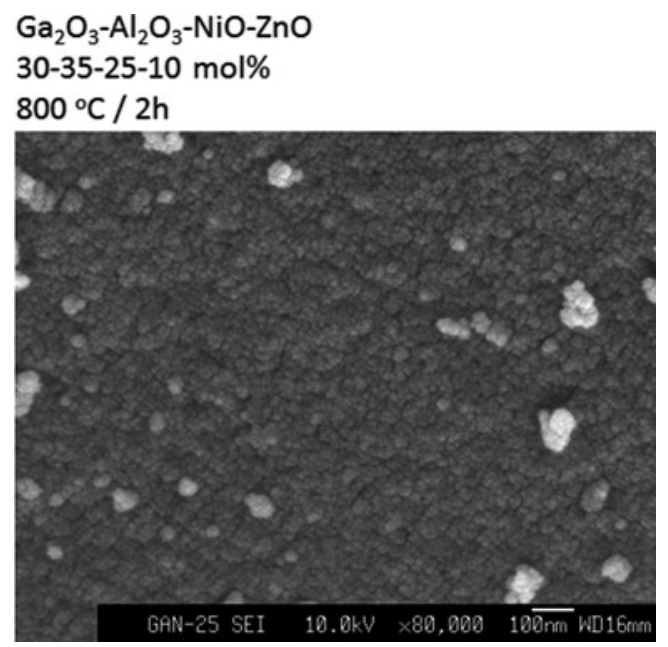

Fig. 2 SEM image of a GANZ powder prepared with the coprecipitation method $(\mathrm{Ga} / \mathrm{Al} / \mathrm{Ni} / \mathrm{Zn}=30: 35: 25: 10 \mathrm{~mol} \%)$. Sample heattreated in air at $800{ }^{\circ} \mathrm{C}$ for $2 \mathrm{~h}$ grains with a width of approximately $3-4 \mathrm{~nm}$ are present (Fig. 3a). The presence of $\{111\}$ facets on the grain surface of $\gamma-\mathrm{Al}_{2} \mathrm{O}_{3}$ was confirmed. Typical diffuse ring patterns assigned to $\gamma-\mathrm{Al}_{2} \mathrm{O}_{3}(400)$ and (440) are visible in the SAED pattern (see the inset in Fig. 3a). Somewhat peanutand/or rod-like particles become evident after the addition of $\mathrm{Ga}_{2} \mathrm{O}_{3}$ into $\gamma-\mathrm{Al}_{2} \mathrm{O}_{3}$. The GANZ powders also contain highly visible rod-like particles. These results indicate that the peanut-type rod-like particles form after the addition and/or during calcination of $\mathrm{Ga}_{2} \mathrm{O}_{3}$ into $\gamma-\mathrm{Al}_{2} \mathrm{O}_{3}$ system. Hamada et al. also found peanut-type rod-like particles in the $\mathrm{Ga}_{2} \mathrm{O}_{3}$ $\mathrm{Al}_{2} \mathrm{O}_{3}$ system [5]. Therefore, it could be anticipated that added $\mathrm{NiO}$ and/or $\mathrm{ZnO}$ might be present on the grain surface of the $\mathrm{Ga}_{2} \mathrm{O}_{3}-\mathrm{Al}_{2} \mathrm{O}_{3}$ solid solution in the form of highly dispersed conditions [7].

$\mathrm{Ga}_{2} \mathrm{O}_{3}-\mathrm{Al}_{2} \mathrm{O}_{3}$ solid solutions have been tested by many research groups as catalysts for the selective reduction of $\mathrm{NO}_{\mathrm{x}} \cdot \mathrm{Ga}_{2} \mathrm{O}_{3}-\mathrm{Al}_{2} \mathrm{O}_{3}$ catalysts exhibit high catalytic activity at high temperatures $[7,8]$. However, their catalytic activity deteriorates in the presence of $\mathrm{H}_{2} \mathrm{O}$ vapor, which is a major component of exhaust gases. Nanostructured spinel-type oxides have attracted great interest because of their unique mechanical strength, electronic properties, and sensitivity. Spinels have been used in various applications including sensors, electronics, nanodevices, and photoelectronics. Kung et al. studied Co-doped $\mathrm{Al}_{2} \mathrm{O}_{3}$ and found that the cobalt species in this system changes from $\mathrm{Co}_{3} \mathrm{O}_{4}$ to $\mathrm{CoAl}_{2} \mathrm{O}_{4}$ (spinel) at $800{ }^{\circ} \mathrm{C}$ and that the activity and selectivity of this catalyst increase upon the formation of the spinel phase [23]. Okazaki et al. found that a similar phenomenon arises for Ni-doped $\mathrm{Al}_{2} \mathrm{O}_{3}$ and concluded that the spinel phase (metal aluminates) is the active metal species in this type of catalyst [24].

We synthesized GANZ spinel powders with the hydrothermal method; a TEM image is shown in Fig. 4a. This morphology is quite different to those obtained with the two other GANZ powder synthesis processes (co-precipitation and sol-gel). The particle sizes of hydrothermally synthesized GANZ are in the range 100-200 $\mathrm{nm}$ and homogeneously dispersed. Some particles look spherical and appear to consist of nanoparticles (Fig. 4a). Figure 4b shows a hydrothermally prepared GANZ powder after processing with wet atomization at a pressure of $150 \mathrm{MPa}$. The atomized GANZ powder (Fig. 4b) has a highly disperse morphology consisting of ultrafine particles. The surface area of this powder is approx. $289 \mathrm{~m}^{2} / \mathrm{g}^{-1}$. It is obvious that this atomization system with a high fluid flow pressure converts the hydrothermally synthesized material into uniform fine particles very effectively within a short time. Note that $\gamma-\mathrm{Al}_{2} \mathrm{O}_{3}$ and $\mathrm{Ga}_{2} \mathrm{O}_{3}-$ $\mathrm{Al}_{2} \mathrm{O}_{3}$ solid solutions with $\gamma-\mathrm{Al}_{2} \mathrm{O}_{3}$ phases are not stable in the presence of $\mathrm{H}_{2} \mathrm{O}$ vapor. Moreover, the GAN sample with a spinel phase prepared by co-precipitation also has very low hydrothermal stability. 

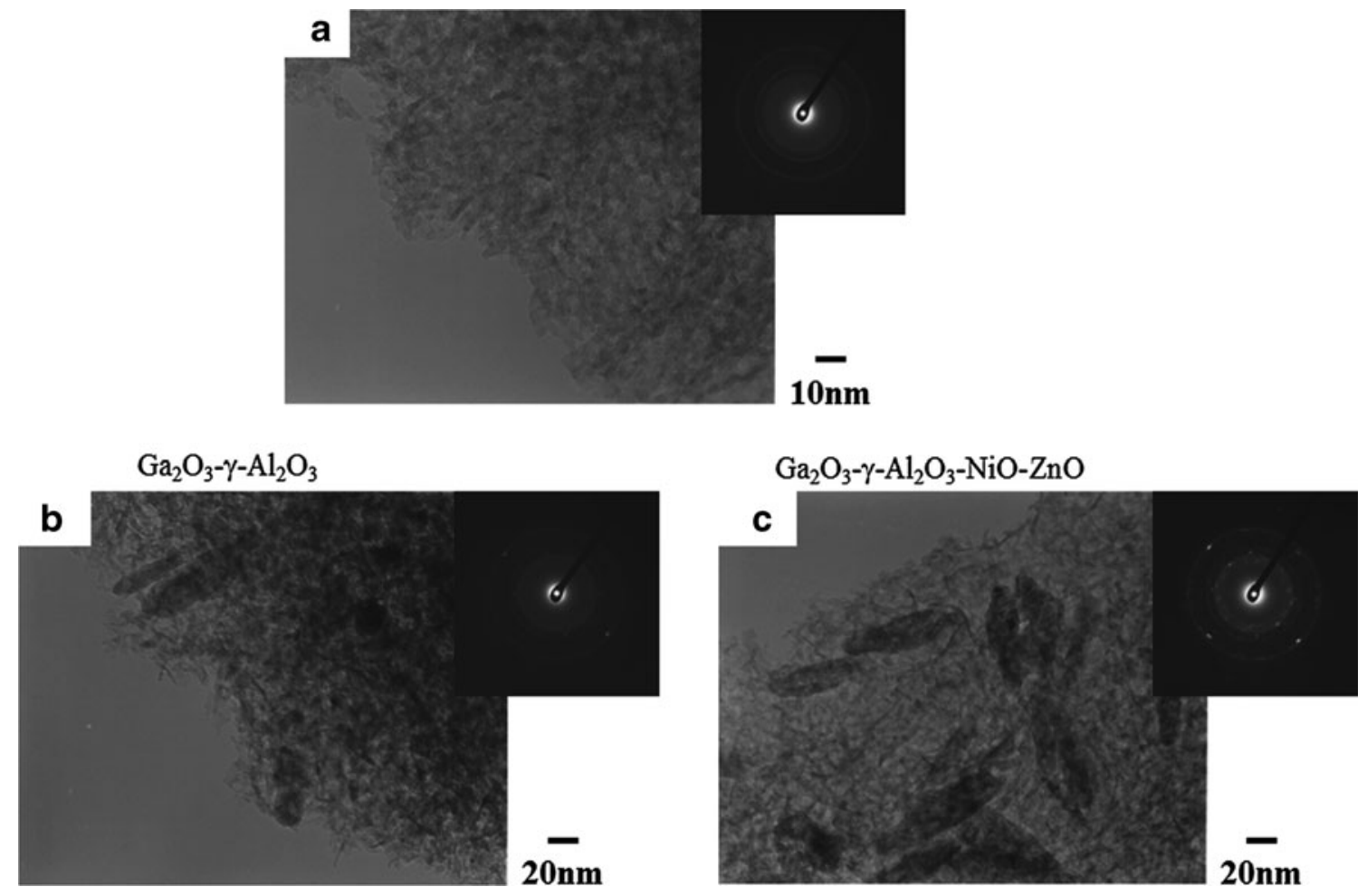

Fig. 3 TEM images of $\mathbf{a} \gamma-\mathrm{Al}_{2} \mathrm{O}_{3}, \mathbf{b} \mathrm{Ga}_{2} \mathrm{O}_{3}-\mathrm{Al}_{2} \mathrm{O}_{3}$, and $\mathbf{c} \mathrm{Ga}_{2} \mathrm{O}_{3}-\mathrm{Al}_{2} \mathrm{O}_{3}-\mathrm{NiO}-\mathrm{ZnO}$; all samples were prepared with the sol-gel method and heat-treated in air at $600{ }^{\circ} \mathrm{C}$ for $2 \mathrm{~h}$

\subsection{Catalytic Performance}

The catalytic activity of a GANZ powder prepared with the hydrothermal and wet atomization processes was tested by using a fixed bed reactor (Fig. 5). The catalytic performances of the GANZ powders in NO reduction by $\mathrm{C}_{2} \mathrm{H}_{4}$ are shown as functions of temperature in Fig. 6. NO reduction commences at approximately $300{ }^{\circ} \mathrm{C}$. The $\mathrm{NO}$ reduction by $\mathrm{C}_{2} \mathrm{H}_{4}$ increases with increases in temperature and reaches its highest activity in the range $380-580^{\circ} \mathrm{C}$, when the $\mathrm{NiO}$ content of the GA system is $25 \%$. In Fig. 6, the effect of $\mathrm{NiO}$ content was examined by keeping the nanocomposite composition $\mathrm{Ga} / \mathrm{Al} / \mathrm{Ni} / \mathrm{Zn}=30: 35:(10$ 30): $10 \mathrm{~mol} \%$, where $30 \mathrm{~mol} \%$ of $\mathrm{Ga}_{2} \mathrm{O}_{3}$ was known to give the highest catalytic activity for de-NOx reactions in the $\mathrm{Ga}_{2} \mathrm{O}_{3}-\mathrm{Al}_{2} \mathrm{O}_{3}$ system [10]. The effect of $\mathrm{ZnO}$ content over GA system has been studied in our previous studies [11-14]. The activity of the $\mathrm{Ga}_{2} \mathrm{O}_{3}-\mathrm{Al}_{2} \mathrm{O}_{3}$ powder is very similar in this temperature range. Figure 6 also shows that the maximum NO reduction activity shifts toward the lower-temperature region as the $\mathrm{NiO}$ content in the GA system increases. In addition, very high catalytic activity was observed after the addition of $\mathrm{NiO} 25 \mathrm{~mol} \%$. It was found that the best composition could be $\mathrm{Ga} / \mathrm{Al} / \mathrm{Ni} /$
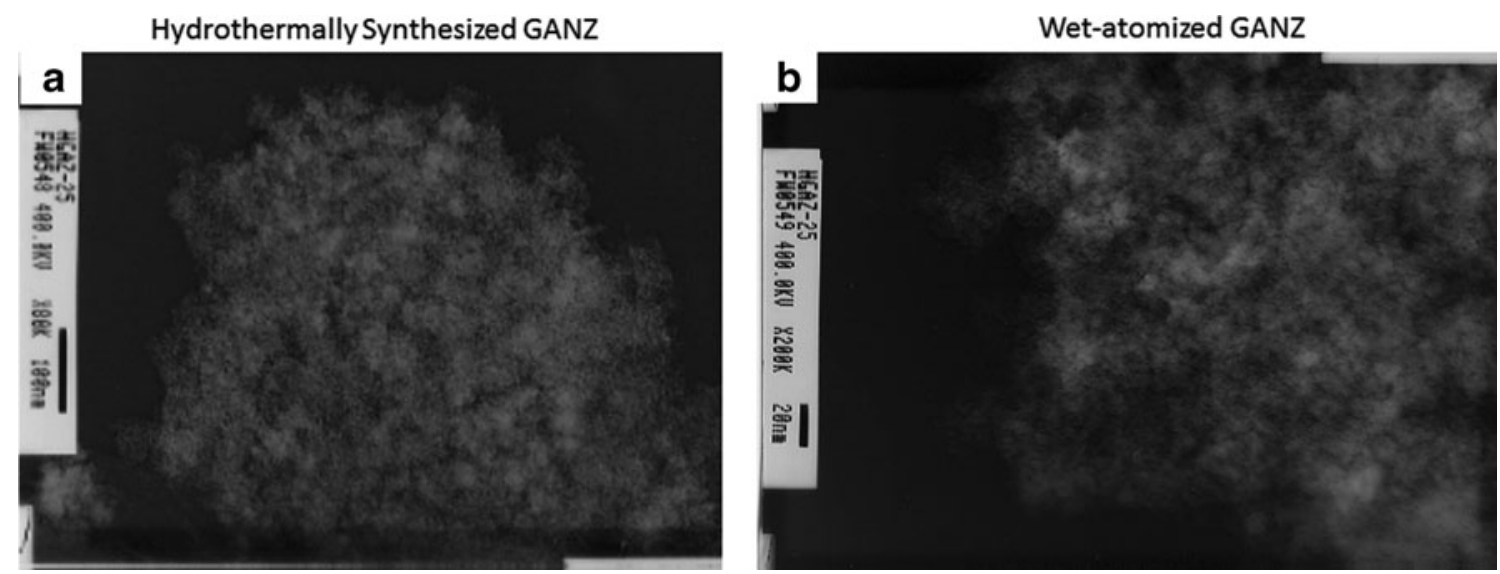

Fig. 4 a TEM image of a GANZ powder prepared with the hydrothermal method. b TEM image of the sample in a after wet atomization 
Fig. 5 Schematic diagram of the catalyst performance testing procedure

\section{Characterization of Catalyst}

Equilibrate $10 \mathrm{~min}$ at each

-Temperature ranging from $100^{\circ} \mathrm{C}$ to $700^{\circ} \mathrm{C} \quad$ Catalyst Granules

Supported by Quartz Wool

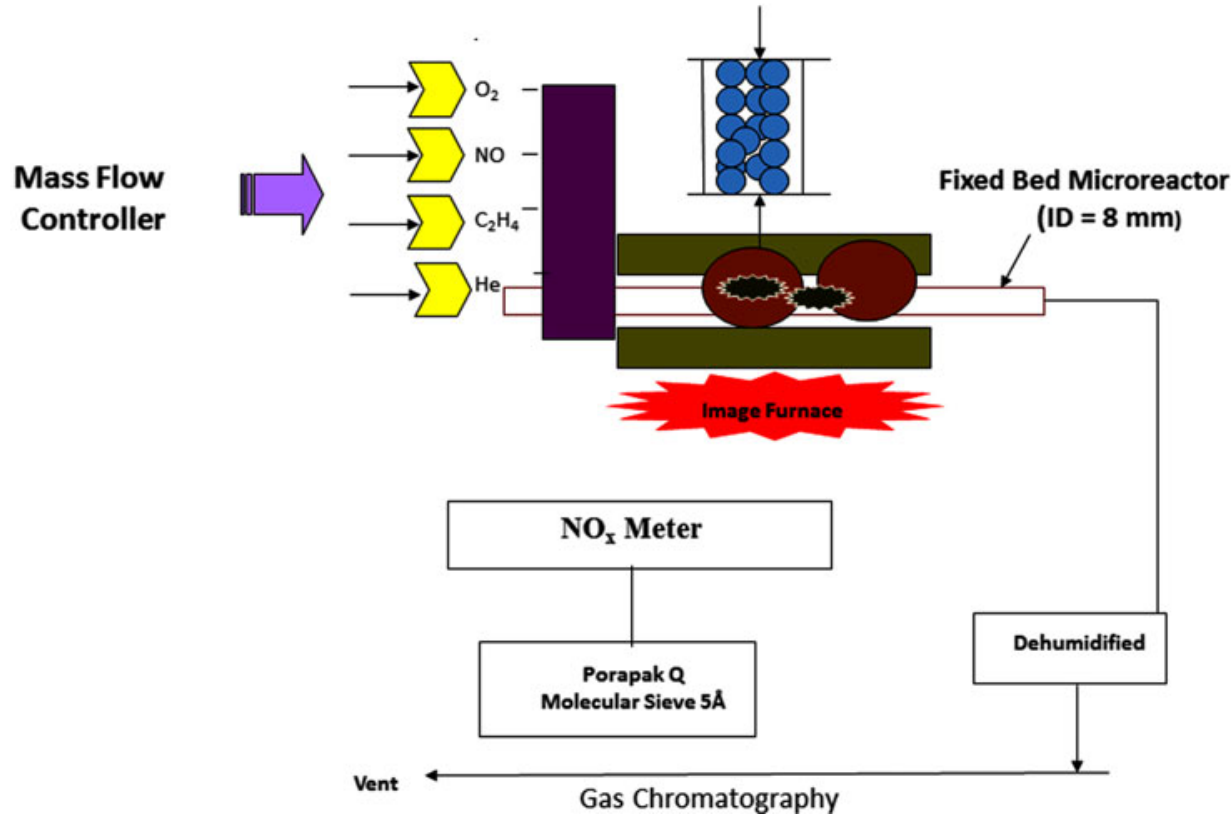

$\mathrm{Zn}=30: 35: 25: 10 \mathrm{~mol} \%$ under the present reaction conditions. The reduction percentage was $99 \%$ in the temperature range from 380 to $580^{\circ} \mathrm{C}$. The high reduction activity with a broad temperature ranges $\left(380-580{ }^{\circ} \mathrm{C}\right)$ was not observed for GA, GAN, and GAZ systems [10-13]. Recently, we have synthesized the GA, GAN, and GAZ with the co-precipitation method and their catalytic activity was tested [10-13]. We have also synthesized GAN and GAZ with the sol-gel and hydrothermal methods.

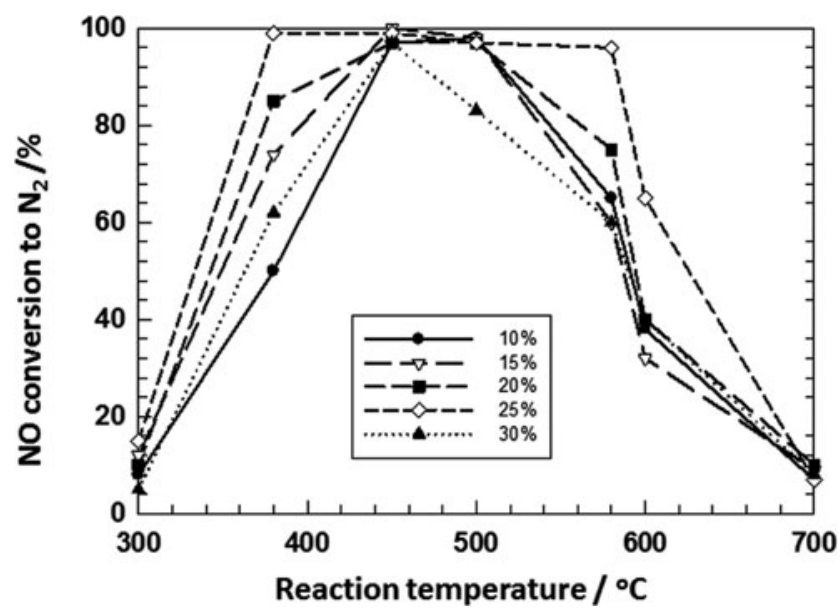

Fig. 6 The catalytic activities of GANZ powders with various $\mathrm{NiO}$ contents (prepared by using the hydrothermal method and processed with wet atomization) in NO reduction as functions of reaction temperature. The reactions proceeded with a feed consisting of $\mathrm{NO}=1000 \mathrm{ppm}, \mathrm{C}_{2} \mathrm{H}_{4}=2000 \mathrm{ppm}$, and $\mathrm{O}_{2}=10 \%$ diluted in $\mathrm{He}$; catalyst weight $=0.18 \mathrm{~g}$; GHSV $20,000 \mathrm{~h}^{-1}$

However, we did not observed the abovementioned high activity covering a broad temperature range.

\subsection{Effect of $\mathrm{H}_{2} \mathrm{O}$ Vapor and $\mathrm{SO}_{2}$ on GANZ}

Most oxide- and zeolite-based catalysts lose significant catalytic activity with time in the presence of $\mathrm{H}_{2} \mathrm{O}$ and $\mathrm{SO}_{2}$ [4]. In this study, the catalytic activities were determined in a mixture consisting of $1000 \mathrm{ppm} \mathrm{NO}, 1000 \mathrm{ppm}_{2} \mathrm{H}_{4}$, and $10 \% \mathrm{O}_{2}$ diluted in $\mathrm{He}$ (Fig. 6). However, when $10 \% \mathrm{H}_{2} \mathrm{O}$ vapor and 3 ppm $\mathrm{SO}_{2}$ were added to this mixture, the $\mathrm{NO}$ conversion to $\mathrm{N}_{2}$ at $500{ }^{\circ} \mathrm{C}$ decreased from 88 to $83 \%$ (Fig. 7). In our

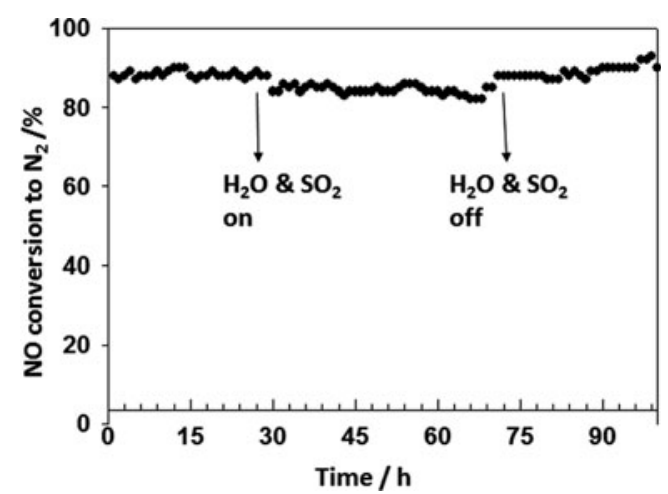

Fig. 7 Durability in the presence of $\mathrm{H}_{2} \mathrm{O}$ vapor and $\mathrm{SO}_{2}$ of a GANZ powder prepared with hydrothermal and wet atomization processes. The reaction was carried out in a feed consisting of $\mathrm{NO}=1000 \mathrm{ppm}$, $\mathrm{C}_{2} \mathrm{H}_{4}=2000 \mathrm{ppm}, \mathrm{O}_{2}=10 \%, \mathrm{H}_{2} \mathrm{O}$ vapor $=10 \%$, and $\mathrm{SO}_{2}=3 \mathrm{ppm}$ diluted with He. GHSV $20,000 \mathrm{~h}^{-1}$ at $500{ }^{\circ} \mathrm{C}$ 
previous study, we observed that the NO conversion decreased in a sequence of Co-ZSM-5 $>$ Ga-ZSM- $5>\mathrm{ZnO}-$ $\mathrm{Ga}_{2} \mathrm{O}_{3}-\mathrm{Al}_{2} \mathrm{O}_{3}$ [9]. GANZ spinel was found to have high durability at $500{ }^{\circ} \mathrm{C}$ for the reduction of $\mathrm{NO}$ by $\mathrm{C}_{2} \mathrm{H}_{4}$ in the presence $10 \%$ water vapor. Figure 7 shows a steady NO conversion for more than $50 \mathrm{~h}$. It is also clear that this effect is fully reversible. The conversion of $\mathrm{NO}$ occurs at a reduced level in the presence of $\mathrm{H}_{2} \mathrm{O}$ vapor and $\mathrm{SO}_{2}$ but returns to its original level when the $\mathrm{H}_{2} \mathrm{O}$ and $\mathrm{SO}_{2}$ feeds are switched off.

No peak is evident for $\mathrm{NiO}$ or $\mathrm{ZnO}$ alone in the XRD pattern. Highly dispersed $\mathrm{NiO}$ and/or $\mathrm{ZnO}$ in the GA system and the spinel phase might have some positive effect to improve the hydrothermal stability. The most remarkable observation of this study is the disappearance of peanut-type rod-like particles from the GANZ system upon wet atomization. This disappearance is due to the two-step synthesis process, which ensures a low agglomeration rate. In addition, this two-step process also significantly increases the catalytic surface area. As a result, very stable catalytic performance was observed for the GANZ system. The large surface area also plays an important role for high catalytic activity in presence of $\mathrm{H}_{2} \mathrm{O}$ vapor (Table 1 ). Research is now in progress to understand the co-relation between calcination temperature and/or synthesis process with the formation of rod-like particles and their disappearance during hydrothermal and atomization process.

The capping and/or inactivation of Lewis acid sites of oxides by water could be the reason for the $5 \%$ reduction in $\mathrm{NO}$ conversion upon exposure to water. The conversion of the reducing agent $\mathrm{C}_{2} \mathrm{H}_{4}$ is also lower under wet conditions than under dry conditions (Fig. 8). The addition of $\mathrm{H}_{2} \mathrm{O}$ vapor may affect the catalytic performance for the oxidation of $\mathrm{C}_{2} \mathrm{H}_{4}$. These results show that the SCR of NO is inversely related to that for $\mathrm{C}_{2} \mathrm{H}_{4}$ conversion. The developed NiO- and $\mathrm{ZnO}-$ doped $\mathrm{Ga}_{2} \mathrm{O}_{3}-\mathrm{Al}_{2} \mathrm{O}_{3}$ composite material is a good candidate for practical use as a $\mathrm{NO}_{\mathrm{x}}$ reduction catalyst. The present synthesis process and the resulting GANZ spinel catalysts could be used in the catalytic removal of NO from the exhaust gases of vehicle engines and industrial boilers.

Table 1 BET surface area, pore volume, and average pore diameter of the GANZ nanocomposites

\begin{tabular}{llll}
\hline & $\begin{array}{l}\text { Surface area } \\
\left(\mathrm{m}^{2} \mathrm{~g}^{-1}\right)\end{array}$ & $\begin{array}{l}\text { Pore volume } \\
\left(\mathrm{cm}^{3} \mathrm{~g}^{-1}\right)\end{array}$ & $\begin{array}{l}\text { Mean pore } \\
\text { diameter }\end{array}$ \\
\hline (1) Co-precipitation & 102 & 0.24 & 6.2 \\
(2) Sol-gel & 200 & 0.62 & 17.4 \\
$\begin{array}{l}\text { (3) Hydrothermal } \\
\text { (4) Hydrothermal and } \\
\text { wet atomization }\end{array}$ & 210 & 0.62 & 16.6 \\
\hline
\end{tabular}

Samples (1) were calcined at $800{ }^{\circ} \mathrm{C}$ for $2 \mathrm{~h}$, and samples (2) were calcined at $600{ }^{\circ} \mathrm{C}$ for $2 \mathrm{~h}$. Samples (3) and (4) were as-synthesized powders

${ }^{\mathrm{a}} \mathrm{BJH}$ method from the adsorption isotherm

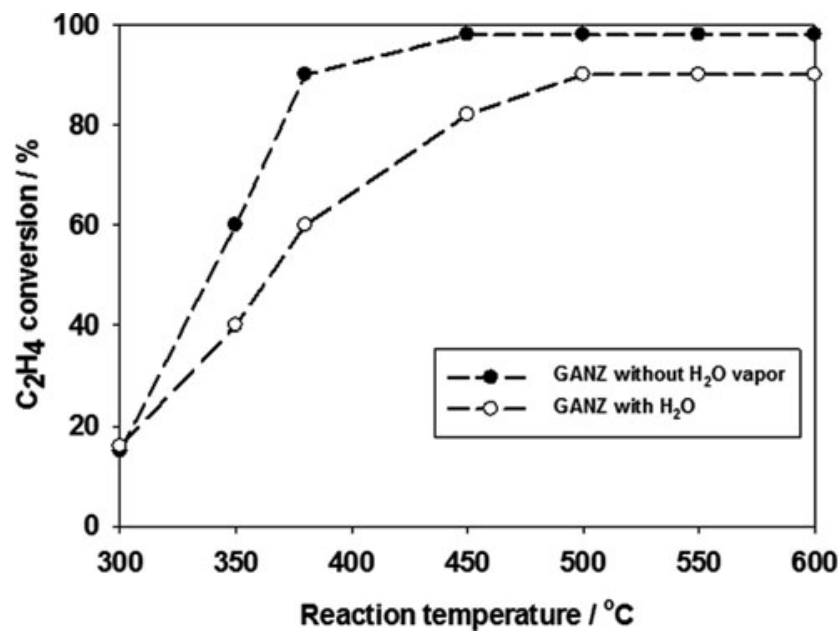

Fig. 8 Conversion of $\mathrm{C}_{2} \mathrm{H}_{4}$ to $\mathrm{CO}_{2}$ over GANZ catalysts prepared with hydrothermal and wet atomization processes under dry (without $\mathrm{H}_{2} \mathrm{O}$ ) and wet (with $\mathrm{H}_{2} \mathrm{O}$ ) conditions as a function of reaction temperature. The reaction conditions are the same as in Fig. 8

\section{Conclusions}

GANZ catalysts were prepared with the co-precipitation, solgel, and hydrothermal methods. The GANZ powders prepared with the hydrothermal method and processed through a wet atomizer were found to be highly effective in NO reduction under real conditions. A steady NO conversion was obtained for more than $50 \mathrm{~h}$ under such conditions. The hydrothermal reaction conditions as well as the pressure and number of cycles of atomization were optimized. The effect of GANZ catalyst preparation by different methods was examined. This is the first report showing GANZ catalysts with a unique hydrothermal stability. GANZ system showed high catalytic activity than those of GA, GAN, and GAZ system. It is an extraordinary finding because no research has yet been reported which shows GANZ nanoparticles stable at high temperature in presence of $\mathrm{H}_{2} \mathrm{O}$ vapor at high space velocity. The high-performance de- $\mathrm{NO}_{\mathrm{x}}$ developed in this study could be considered for industrial applications.

Acknowledgments The authors would like to acknowledge the support provided by King Abdulaziz City for Science and Technology (KACST) through the Science \& Technology Unit at King Fahd University of Petroleum \& Minerals (KFUPM) for funding this work through project no. AT-32-21.

\section{References}

1. Bosch, H., Janssen, F.: Catalytic reduction of nitric oxides-a review of the fundamentals and technology. Catal. Today 2, 369-521 (1988)

2. Baird, C., Chann, M. (eds.): Environmental Chemistry, Fourthth edn, pp. 145-173. W.H. Freeman and Company, New York (2008)

3. Luo, Y.M., Hao, J.M., Hou, Z.Y., Fu, L.X., Li, R.T., Ning, P., Zheng, X.M.: Influence of preparation methods on selective 
catalytic reduction of nitric oxides by propene over silver-alumina catalyst. Catal. Today 93, 797-803 (2004)

4. Shelef, M.: Selective catalytic reduction of NO, with $\mathrm{N}$-free reductants. Chem. Rev. 95, 209-225 (1995)

5. Matsumoto, S.: Recent advances in automobile exhaust catalysts. Catal. Today 90, 183-190 (2004)

6. Pitukmanorom, P., Ying, J.Y.: Selective catalytic reduction of nitric oxide by propene over $\mathrm{In}_{2} \mathrm{O}_{3}-\mathrm{Ga}_{2} \mathrm{O}_{3}-\mathrm{Al}_{2} \mathrm{O}_{3}$ nanocomposites. Nano Today 4, 220-226 (2009)

7. Haneda, M., Kintaichi, Y., Shimada, H., Hamada, H.: Selective reduction of $\mathrm{NO}$ with propene over $\mathrm{Ga}_{2} \mathrm{O}_{3}-\mathrm{Al}_{2} \mathrm{O}_{3}$ : effect of solgelmethod on the catalytic performance. J. Catal. 192, 137-148 (2000)

8. Zhiming, L., Seong, I.W.: Recent advances in catalytic DeNO science and technology. Catal. Rev. 48, 43-89 (2006)

9. Zahir, M.H., Katayama, S., Awano, M.: Hydrothermal synthesis of $\mathrm{ZnO}-\mathrm{Ga}_{2} \mathrm{O}_{3}-\mathrm{Al}_{2} \mathrm{O}_{3}$ spinel for $\mathrm{NO}$ reduction by hydrocarbon under oxygen-rich conditions. Catal. Lett. 93, 145-150 (2004)

10. Zahir, M.H., Katayama, S., Awano, M.: Synthesis and de-NO properties of $\mathrm{ZnO}-\mathrm{Ga}_{2} \mathrm{O}_{3}-\mathrm{Al}_{2} \mathrm{O}_{3}$ spinel. Mater. Chem. Phys. 86, 99-104 (2004)

11. Zahir, M.H.: Influences of heat treatment and DeNOx performance of cordierite honeycombs washcoated with spinel catalysts. Mater. Chem. Phys. 130, 1038-1045 (2011)

12. Trueba, M., Trasatti, S.P.: Alumina as a support for catalysts: a review of fundamental aspects. Eur. J. Inorg. Chem. 3393-3403 (2005)

13. Zahir, M.H., Alhooshani, K., Masumder, M.A.J., Suzuki, T.: Multicomponent catalysts with spinel structure for the selective reduction of nitrogen oxide by ethylene in lean-exhaust gas streams. Kinet. Catal. 54, 578-585 (2013)

14. Shimizu, K., Satsuma, A., Hattori, T.: Selective catalytic reduction of $\mathrm{NO}$ by hydrocarbons on $\mathrm{Ga}_{2} \mathrm{O}_{3}-\mathrm{Al}_{2} \mathrm{O}_{3}$ Catalysts. Appl. Catal. B Environ. 16, 319-326 (1998)
15. Jeevanandam, P., Kotypin, Y., Gedanken, A.: Preparation of nanosized nickel aluminate spinel by a sonochemical method. Mater. Sci. Eng. 90, 125-132 (2002)

16. Aguilar-Rios, G., Valenzuela, M., Salas, P., Armendariz, H., Bosch, P., Toro, G.D., Silva, R., Bertin, V., Castillo, S., Ramirez-Solis, A., Schifter, I.: Hydrogen interactions and catalytic properties of platinum-tin supported on zinc aluminate. Appl. Catal A 127, 65-75 (1995)

17. Słoczyński, J., Ziółkowski, J., Grzybowska, B., Grabowski, R., Jachewicz, D., Wcisło, K., Gengembre, L.: Oxidative dehydrogenation of propane on $\mathrm{Nix} \mathrm{Mg}_{1}-x \mathrm{Al}_{2} \mathrm{O}_{4}$ and $\mathrm{NiCr}_{2} \mathrm{O}_{4}$ spinels. $\mathrm{J}$. Catal. 187, 410-418 (1999)

18. Otero Areán, C., Penarroya Mentruit, M., López López, A.J., Parra, J.B.: High surface area nickel aluminate spinels prepared by a solgel method. Colloids Surf. A Physicochem. Eng. Asp. 180, 253258 (2001)

19. Nordahl, C.S., Messing, G.L.: Transformation and densification of nanocrystalline $\gamma-\mathrm{Al}_{2} \mathrm{O}_{3}$ during sinter forging. J. Am. Ceram. Soc. 79, 3149-3154 (1996)

20. Dawson, W.J.: Hydrothermal synthesis of advanced ceramic powders. Am. Ceram. Soc. Bull. 67, 1673-1678 (1988)

21. Zahir, M.H., Suzuki, T., Yamaguchi, T., Fujishiro, Y., Awano, M.: Wet atomisation of $\mathrm{Gd}$-doped $\mathrm{CeO}_{2}$ electrolyte slurries for intermediate temperatures'microtubular SOFC applications. Fuel Cells 9 , 164-169 (2009)

22. Navrotsky, A., Wechsler, B.A., Geisinger, K., Seifert, F.: Thermochemistry of $\mathrm{MgAl}_{2} \mathrm{O}_{4}-\mathrm{Al}_{8 / 3} \mathrm{O}_{4}$ defect spinels. J. Am. Ceram. Soc. 69, 418-422 (1986)

23. Yan, J.Y., Kung, M.C., Sachtler, W.M.H., Kung, H.H.J.: $\mathrm{Co} / \mathrm{Al}_{2} \mathrm{O}_{3}$ lean NOx reduction catalyst. J. Catal. 172, 178-186 (1997)

24. Okazaki, N., Katoh, Y., Shiina, Y., Tada, A., Iwamoto, M.: Selective suppression of undesirable competitive oxidation during selective catalytic reduction of nitrogen monoxide by ethene in excess oxygen over metal-loaded aluminas. Chem. Lett. 9, 889-890 (1997) 